\title{
Visualisation of Rouviere's Sulcus during laparoscopic cholecystectomy
}

\author{
Prabin Bikram Thapa,' Dhiresh Kumar Maharjan,' Theten Yonjan Tamang,' Suman Kumar Shrestha' \\ 'Department of Surgery, Kathmandu Medical College Teaching Hospital, Sinamangal, Kathmandu, Nepal.
}

\section{ABSTRACT}

Introduction: Safe dissection of Calot's Triangle is important during the performance of laparascopic cholucystectomy. The purpose of the study is to determine the frequency of demonstrable Rouviere's sulcus in patients with symptomatic gall stones and its role in safe dissection in Calot's triangle.

Methods: This is a prospective descriptive study design done in Department of surgery, Kathmandu Medical College Teaching Hospital from Jan 2013 to Jan 2015. Patients who were posted for laparoscopic cholecystectomy were included. During laparoscopy, Rouviere's sulcus was noted in the operative note and classified according to following: Type I: Open type was defined as a cleft in which the right hepatic pedicle was visualized and the sulcus was opened throughout its length. Type II: if the sulcus was open only at its lateral end. Type III If the sulcus was open only at its medial end. Type IV: Fused type was defined as one in which the pedicle was not visualized.

Results: A total of 200 patients underwent laparoscopic cholecystectomy during period of 2 years. Out of which Rouviere's sulcus was visualized in 150 patients (75\%).Type I (open type) was commoner in $54 \%$, type II in $12 \%$, Type III in $9 \%$ and type IV (fused type) in $25 \%$.

Conclusion: Rouviere's Sulcus is an important extra biliary land mark for safe dissection of Calot's triangle during laparoscopic cholecystectomy.

Keywords: Rouviere's Sulcus, Laparoscopic cholecystectomy, Bile duct injury.

\section{INTRODUCTION}

Laparoscopic cholecystectomy have been gold standard treatment for gall stone disease. With advent of new procedure in 1990s, there was sharp rise in incidence of surgical related complications ranging from incidence of bile duct injury $0.6 \%$, vascular injury $0.14 \%$,bowel injury $0.25 \%$ which was higher than conventional open cholecystectomy. ${ }^{1-6}$ However, with development of newer surgical instruments with high definitions monitors and decrease in learning curve for surgical procedure, there has been dramatic decrease in the incidence of biliovascular injury. Beside critical view of safety as stated by Strassberg et al ${ }^{7}$," two parallel structure running parallel towards gall bladder" helps to reduce biliovascular injury. Most of the time role of Rouviere's sulcus have been less prioritized during this dissection though it's importance have been mentioned by papers..$^{8-11}$

Hence we try to identify the presence and type of Rouviere's sulcus in our population and assess whether

Correspondence: Dr. Prabin Bikram Thapa, Department of Surgery, Kathmandu Medical College Teaching Hospital, Sinamangal, Kathmandu, Nepal Email:prabinbł@gmail.com, Phone: +977. 9851002303. 
it helps to lessen the incidence of biliovascular injury at our set up.

\section{METHODS}

This prospective cross sectional descriptive study was conducted from Jan 2013-Jan 2015 in Unit III, Department of Surgery, Kathmandu Medical College Teaching Hospital, Sinamangal, Nepal. First 200 patients who were admitted for laparoscopic cholecystectomy for symptomatic gallstone disease were enrolled after taking informed consent according to Helsinki's declaration. During laparoscopic cholecystectomy, standard three abdominal ports were made and routinely identification and photographic documentation of Rouviere's Sulcus and classification was done. Then posterior leaf of the peritoneum covering the hepatobiliary triangle was released and final confirmation of the critical view of safety " two parallel structure running parallel towards gall bladder" was achieved before clipping of cystic duct and artery. If conversion to open cholecystectomy needed, reason was documented and any incidence of bile duct injury was documented.

\section{Classification of Rouviere's Sulcus:}

Type I: Open type was defined as a cleft in which the right hepatic pedicle was visualized and the sulcus was opened throughout its length. (Figure 1)

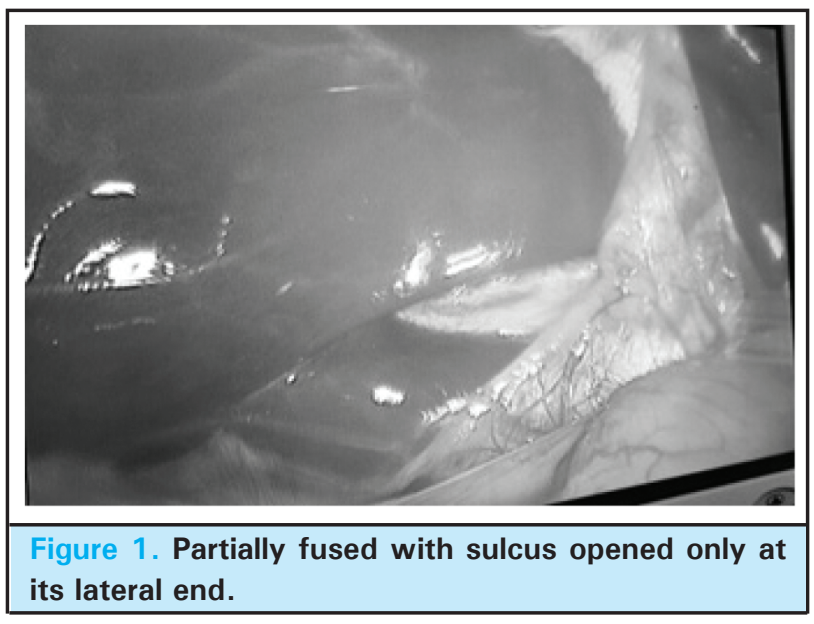

Type II: Partially fused with sulcus opened only at its lateral end. (Figure 2)

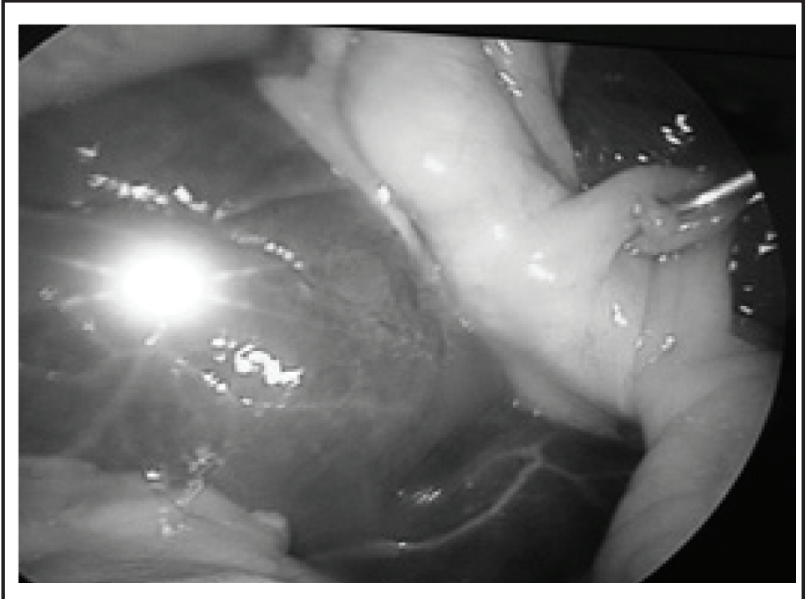

Figure 2. Partially fused

Type III: Partially fused with sulcus opened only at its medial end. (Figure 3)

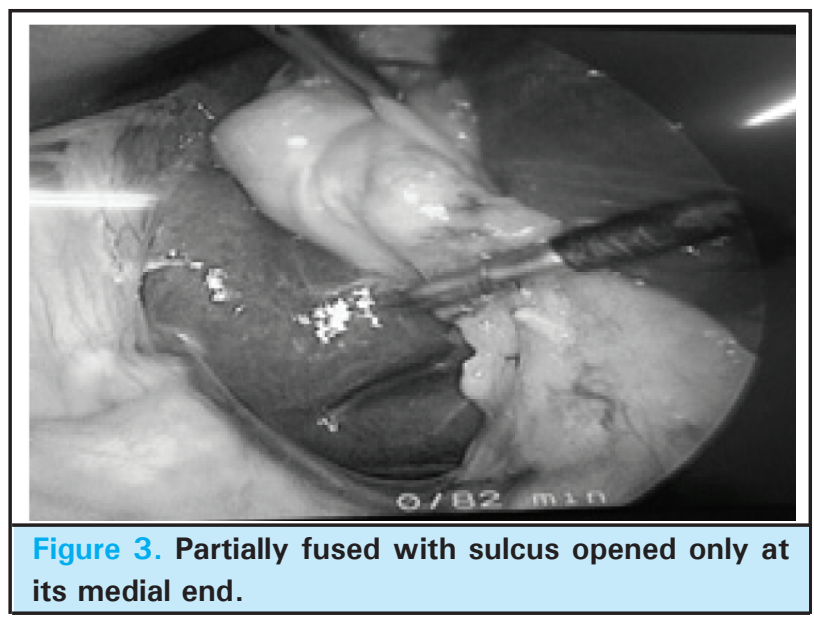

Type IV: Fused type was defined as one in which the pedicle was not visualized or absent sulcus. (Figure 4)

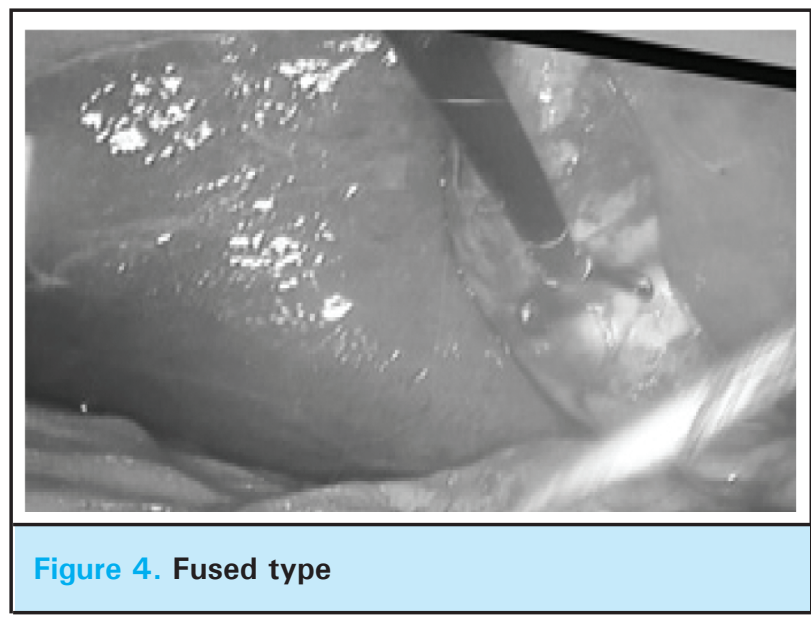




\section{RESULTS}

A total of 200 patients underwent laparoscopic cholecystectomy for different indications (Table 1) during period of 2 years. Among them two had conversion to open $(0.01 \%)$ due to dense adhesion at Calot's triangle (Table 2).Out of which Rouviere's sulcus was visualized in 150 patients (75\%).Type I (open type) was commoner in $54 \%$, type II in $12 \%$, Type III in $9 \%$ and type IV (fused type) in $25 \%$. (Figure V).

\begin{tabular}{|ll|}
\hline Table 1: \\
\hline Indications for Surgery & \\
Symptomatic Cholelithiasis & 128 \\
Acute Calculus Cholecystitis & 50 \\
Acute Biliary pancreatitis & 15 \\
Gall bladder polyp & 7 \\
\hline
\end{tabular}

\begin{tabular}{|ll|}
\hline \multicolumn{2}{|l|}{ Table 2. Demographic representation: } \\
\hline Mean age & $55 \pm 10$ years \\
M:F ratio & $1: 1.56(78 / 122)$ \\
Conversion rate & 2 patients $(0.01 \%)$ \\
Reason for & $\begin{array}{l}\text { Dense adhesion in Calot's } \\
\text { triangle due to previous } \\
\text { conversion : }\end{array}$ \\
& surgery \\
Bile Duct Injury & Nil \\
\hline
\end{tabular}

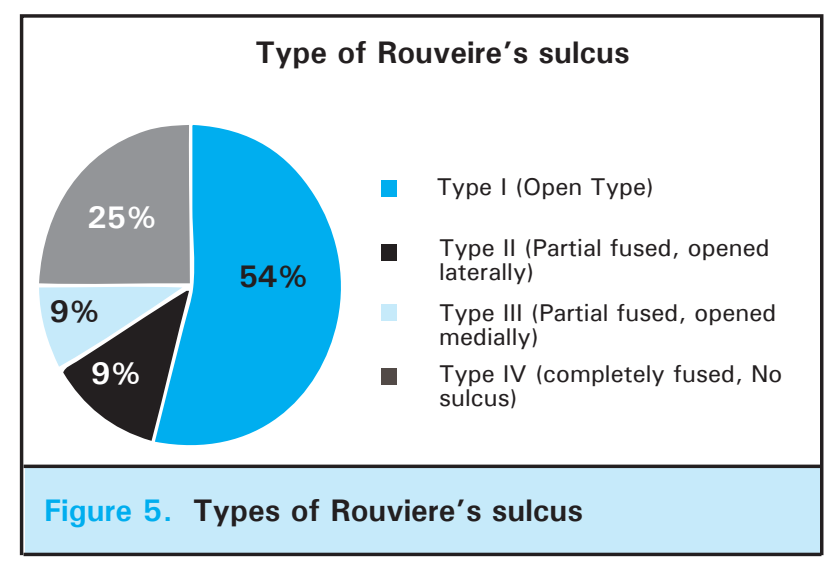

\section{DISCUSSION:}

Rouviere's sulcus was described in 1924 by Henri Rouviere ${ }^{12}$. It is a 2 - to $5-\mathrm{cm}$ sulcus running to the right of the liver hilum anterior to the caudate process and usually containing the right portal triad or its branches. This sulcus usually indicates the plane of common bile duct precisely. Identification of the sulcus requires anterosuperior and leftward traction of the gallbladder neck, with exposure and dissection of the posterior hepatobiliary triangle bounded by the neck of the gallbladder, the liver surface, and the plane of the sulcus. Dissection may be started safely by division of the peritoneum immediately ventral to the sulcus. Some of papers have quoted that starting Rouviere's sulcus as a starting extrabiliary fixed point before starting dissection helps to identify cystic duct and cystic artery earlier as its lies just above it thus confirming the anatomy of Calot's triangle. ${ }^{13,14}$ This sulcus have been an important anatomical landmark while performing right hepatectomy as well. ${ }^{15,16}$

In our sample study population, open Rouviere's sulcus was commoner than a fused type, where as in paper by Muhammad $\mathrm{Z}$ et al $^{17}$ in Pakistani population fused type was common $55.96 \%$ than a open sulcus type $44.04 \%$. However, study done in Slovenia by Raja Dahmane ${ }^{18}$, showed

that frequency of the Rouviere's sulcus was $82 \%$. Open Rouviere's sulcus was identified in $70 \%$ of the livers The fused type was observed in $12 \%$ of the cases whereas $18 \%$ of the livers had no sulcus.

Post laparoscopic era for gall stone disease have shown rise in incidence of complex surgical complications which were unknown during open surgery era. There was more complex biliovascular injury than single organ injury like biliary or vascular or bowel. This have been related with lack of laparoscopic anatomy knowledge, with lack of tactile feedback and two dimensional vision, however it's because of false judgment of surgeon or spatial disorientation during surgery relating to complex biliovascular injury even in hands of expertise. ${ }^{19,20}$

Hence, different methods were proposed in order help to reduce the risk of bile duct injury including routine use of intraoperative cholangiography. ${ }^{21-24}$ One of the major issues concern misidentification and loss of awareness of the surroundings during laparoscopic cholecystectomy which are subsequently reinforced by cognitive fixation and plan continuation ${ }^{25}$ and even reinforced by team approach where two surgeons make decision before clipping or cutting cystic duct or artery. ${ }^{26}$ Connor SJ et al have even pushed forward in creating a standardized method for laparoscopic cholecystectomy to create a concept operation-specific checklist which can further prevent bile duct injury. ${ }^{27}$

\section{CONCLUSIONS}

Rouviere's Sulcus is an important extra biliary land mark for safe dissection of Calot's triangle during laparoscopic cholecystectomy. 


\section{REFERENCES}

1. Johnston GW. Iatrogenic bile duct stricture: an avoidable surgical hazard? Br J Surg 1986; 73: 245-47.

2. Cuschieri A, Dubois F, Mouiel J. The European experience with laparoscopic cholecystectomy. Am J Surg 1991; 161: 382-7.

3. The Southern Surgeons Club. A prospective analysis of 1,518 laparoscopic cholecystectomies. N Eng J Med 1991;324: 1073-1078

4. Baily RW, Zucker KA, Flowers JL Laparoscopic cholecystectomy experience with 375 consecutive patients. Ann Surg 1991;214: 531-41.

5. Adams DB, Mark RB, Wootton III FT, Cunningham JT. "Bile duct complications after laparoscopic cholecystectomy." Surg Endosc 1993;7(2):79-83.

6. Deziel DJ, Millikan KW, Economou SG, Doolas A, KoST,Airan MC. Complications of laparoscopic cholecystectomy. A national survey of 4292 hospitals and an analysis of 77604 cases. Am. J. Surg. 1993; 165: 9-14.

7. Strassberg SM, Hertl M, Soper NJ. An analysis of the problem of biliary injury during laparoscopic cholecystectomy. J Am Coll Surg 1995; 180: 101-25.

8. Hugh TB, Kelly MD, Mekisic A. Rouviere's sulcus: A useful landmark in laparoscopic cholecystectomy. Br. J. Surg. 1997; 84:1253-4.

9. Slater K, Strong RW, Wall DR, Lynch SV. "Iatrogenic bile duct injury: the scourge of laparoscopic cholecystectomy." ANZ J Surg. 2002 Feb; 72(2):83-8.

10. Nagral S. "Anatomy relevant to cholecystectomy." J Minim Access Surg. 2005 Jun; 1(2):53-8.

11. Singh, K, Ohri A. "Anatomic landmarks: their usefulness in safe laparoscopic cholecystectomy." Surg Endosc. 2006 Nov; 20(11):1754-8.

12. Rouviere H. Sur la configuration et la signification du sillon $\mathrm{du}$ processus caude. Bulletins et memoires de la societe Anatomique de Paris 1924;94: 355-358

13. Hugh TB. "New strategies to prevent laparoscopic bile duct injury—surgeons can learn from pilots." Surgery 2002; 132(5): 826-835.
14. Zha Y, Chen XR, Luo D, Jin Y. The prevention of major bile duct injures in laparoscopic cholecystectomy: the experience with 13,000 patients in a single center. Surg Laparosc Endosc Percutan Tech. 2010 Dec; 20(6):378-83.

15. Kawarada Y, Das BC, Taoka H. "Anatomy of the hepatic hilar area: the plate system." J Hepatobiliary Pancreat Surg. 2000; 7(6):580-6.

16. Mouly C, Fuks D, Browet F, Mauvais F, Potier A, Yzet T, Quentin Q, Regimbeau JM . Feasibility of the Glissonian approach during right hepatectomy. НРB(oxford) 2013; 15(8): 638-45.

17. Muhammad Z, Lubna H, Farzana M, Masoom RM, Mehmood AK, Quraishy MS. "Rouviere's sulcus: a guide to safe dissection and laparoscopic cholecystectomy." Pak J Surg 2009; 22(2): 119-21.

18. Dahmane, R, Morjane A, Starc A. Anatomy and surgical relevance of Rouviere's sulcus. ScientificWorldJournal. 2013 Nov 6; 2013: 254287.

19. Connor S, Garden OJ. Bile duct injury in the era of laparoscopic cholecystectomy. Br J Surg 2006; 93(2):158-68.

20. Way LW, Stewart L, Gantert W, et al. Causes and prevention of laparoscopic bile duct injuries: Analysis of 252 cases from a human factors and cognitive psychology perspective. Ann Surg 2003; 237:460-69.

21. Sanjay P, Fulke JL, Exon DJ. Critical view of safety as an alternative to routine intraoperative cholangiography during laparoscopic cholecystectomy for acute biliary pathology. J Gastrointest Surg 2010; 14:1280-4

22. Ludwig K, Bernhardt J, Steffen H, Lorenz D. Contribution of intraoperative cholangiography to incidence and outcome of common bile duct injuries during laparoscopic cholecystectomy. Surg Endosc 2002; 16:1098-104.

23. Fletcher DR, Hobbs MS, Tan P, et al. Complications of cholecystectomy: Risks of the laparoscopic approach and protective effects of operative cholangiography: A population-based study. Ann Surg 1999; 229:449-57.

24. Ishizawa T, Bandai Y, Ijichi M, Kaneko J, Hasegawa K, Kokudo N. Fluorescent cholangiography illuminating the biliary tree during laparoscopic cholecystectomy. Br J Surg 2010; 97: 1369-77.

25. Reason J. Human error: Models and management. Br Med J 2000; 320:768-70.

26. Hunter JG. Avoidance of bile duct injury during laparoscopic cholecystectomy. Am J Surg 1991; 162:71-76.

27. Connor SJ, Perry W, Nathanson L, Hugh TB, Hugh TJ . Using a standardized method for laparoscopic cholecystectomy to create a concept operation-specific checklist. HPB 2014; 16(5): 422-429. 